\title{
Comparison of prevalence of hypercalciuria after intravenous injection of ceftriaxone versus ampicillin and cefotaxime in children with febrile infection
}

\author{
Maryam Esteghamati ${ }^{1}$, Nadia Parvar ${ }^{2}$, Kambiz Ghasemi $^{1}$
}

\begin{abstract}
${ }^{1}$ M.D., Pediatric Nephrologist, Assistant Professor, Clinical Research Development Center of Children Hospital, Hormozgan University of Medical Sciences, Bandar Abbas, Iran

${ }^{2}$ M.D., Pediatrician, Clinical Research Development Center of Children Hospital, Hormozgan University of Medical Sciences, Bandar Abbas, Iran
\end{abstract}

\section{Type of article: Original}

\begin{abstract}
Background and aim: Ceftriaxone is a third generation Cephalosporin and is often used to treat infections of the upper gastrointestinal tract and urinary tract infections. Due to some reported side effects of these drugs, such as urinary stone formation which may be related to hypercalciuria, this study aimed to determine the effect of ceftriaxone in the treatment of urinary tract infection with urinary stone formation.

Methods: This cross-sectional study was carried out on 120 children from the age of 2 months to 14 years with febrile infections admitted to the Children's Hospital of Bandar Abbas in 2016. Patients were randomly allocated to two groups: The first group received a dose of ceftriaxone $100-50 \mathrm{mg} / \mathrm{kg}$ every 12 hours (depending on severity) and in the second group, ampicillin $50 \mathrm{mg} / \mathrm{kg}$ every 6 hours and cefotaxime $50 \mathrm{mg} / \mathrm{kg}$ every 8 hours were administered. For evaluation of hypercalciuria calcium to creatinine ratio (ca/cr) in random urine was used. Hypercalciuria was defined as $\mathrm{Ca} / \mathrm{Cr}>0.6$ in infants $<1$ years old and $\mathrm{Ca} / \mathrm{Cr}>0.2$ in infants $>1$ year old. Data was analyzed by IBM-SPSS version 21 through descriptive statistics, Chi-square, Fisher's exact test, independent samples t-test, and paired samples t-test. P-value less than 0.05 was considered significant.

Results: A total of 120 children were enrolled in the study (78 in the ceftriaxone group vs. 42 in the ampicillin and ceftriaxone group). Both groups were similar in terms of age, gender, creatinine ratio and pre-treatment $\mathrm{Ca} / \mathrm{Cr}$ ratio, but the difference between the groups was compared after treatment $(0.339 \pm 0.204$ in the ceftriaxone group and $0.236 \pm 0.159$ in ampicillin and cefotaxime group) ( $\mathrm{p}=0.005)$. The prevalence of hypercalciuria in the group receiving ceftriaxone, $15(19.2 \%)$ and in the group receiving Ampicillin $2(4.8 \%)(p<0.03)$.

Conclusion: According to the information obtained from this study, we found out that ceftriaxone can increase the risk of hypercalciuria. Further studies with different populations could help to raise awareness of this issue.

Keywords: Ceftriaxone, Cefotaxime, Hypercalciuria
\end{abstract}

\section{Introduction}

\subsection{Background and statement of problem}

Fever is the most common cause of referral to health centers in children. Often, the etiology of fever is evident by physical examination and para-clinics. Bacterial infections are common etiology of fever, which can be treated with suitable antibiotics. Ceftriaxone is the treatment of choice for upper respiratory tract infections (pneumonia, otitis media) and urinary tract (pyelonephritis). Also, a combination of cefotaxime and ampicillin can be used with suitable coverage of gram positive and gram negative bacterial agents with synergistic effects (1). Ceftriaxone and ampicillin and cefotaxime, are common antibiotics used for febrile infections in children. Some studies have reported the increased risk of renal stone with ceftriaxone. The evidences in this regard are inadequate. Plasma half-

\section{Corresponding author:}

Dr. Nadia Parvar, Clinical Research Development Center of Children Hospital, Hormozgan University of Medical Sciences, Bandar Abbas, Iran. Tel: +98.9177634332, Email: nadia.parvar@gmail.com

Received: March 26, 2017, Accepted: November 23, 2017, Published: March 2019

iThenticate screening: November 28, 2017, English editing: February 12, 2018, Quality control: March 18, 2018

This article has been reviewed / commented by three experts

Ethics approval: HUMS.REC.1394.140

(C) 2018 The Authors. This is an open access article under the terms of the Creative Commons Attribution-NonCommercialNoDerivs License, which permits use and distribution in any medium, provided the original work is properly cited, the use is non-commercial and no modifications or adaptations are made. 
life of ceftriaxone is 6 to 9 hours, and is higher in neonates. About $55 \%$ of its single dose excretes in urine and $45 \%$ excretes in the biliary tract which causes some complications in the biliary system (2-4). Common side effects are anemia, thrombocytopenia, hemolysis, nephrolithiasis, colitis, pseudocholelitiasis, and biliary sludge $(5,6)$. Recent evidence shows that ceftriaxone can cause hypercalciuria. Ampicillin is widely used for infections of urinary and respiratory infections and meningitis (7). Cefotaxime is a third generation cephalosporine which is used in respiratory, urinary, and skin infections and in peritonitis, and meningitis. Side effects such as hypercalciuria and biliary sludge are not reported in ampicillin use (7). Widespread use of ceftriaxone in febrile infections in children increases the risk of hypercalciuria and renal stones and gallbladder stones in these patients. Ampicillin and cefotaxime have similar anti-bacterial effects with no risk of hypercalciuria or renal stones. The exact mechanisms of ceftriaxone induced hypercalciuria is not clear. Also, limited evidence is available for prevalence of ceftriaxone induced hypercalciuria. More studies are needed to obtain enough evidence which can be applicable in management of patients with febrile infections.

\subsection{Objectives}

The general objective of this study was to compare the prevalence of hypercalciuria after intravenous injection of ceftriaxone versus ampicillin and cefotaxime in children with febrile infection in a pediatric hospital in Bandar Abbas in 2016.

\section{Material and Methods}

\subsection{Study design and setting}

This study was conducted on 120 children with fever and bacterial infection between 2 months and 14 years old referred to a pediatric hospital in Bandar Abbas in 2016.

\subsection{Sampling}

Considering the power of $80 \%$ and confidence interval of $95 \%$ and standard deviation of 0.16 for $\mathrm{Ca} / \mathrm{Cr}$ ratio, a sample size of at least 93 patients were calculated to determine the difference of $0.1 \mathrm{in} \mathrm{Ca} / \mathrm{Cr}$ ratio in two groups (8). Using convenience sampling, we selected 120 children from 2 months to 14 years old who were referred to a pediatric hospital in 2016, and were diagnosed to have bacterial febrile infection requiring ceftriaxone or ampicillin and cefotaxime. Convenience sampling helped us to reach the sample size with lower costs and to save time. Patients were randomly assigned into two groups either to receive $50-100 \mathrm{mg} / \mathrm{kg}$ ceftriaxone (based on disease severity) or ampicillin $50 \mathrm{mg} / \mathrm{kg}$ every 6 hours, and cefotaxime $50 \mathrm{mg} / \mathrm{kg}$ every 8 hours.

\subsection{Outcomes}

For assessment of hypercalciuria calcium to creatinine, ratio of random spot urine sample $(\mathrm{mg})$ were used at 24 hours after antibiotic administration. Measures above 0.6 in neonates less than 1 years old and measures above 0.2 in children above 1 year were assumed to be hypercalciuria.

\subsection{Data collection}

For each patient, a checklist including demographic information (age, gender, place of residence, etc.), urine calcium to creatinine ratio before treatment and 48 hours after treatment were completed.

\subsection{Ethical issues}

A written informed consent was obtained from all the parents. Patients' information was kept confidential. The study is approved by the Ethics Committee of Hormozgan University of Medical Sciences (HUMS.REC.1394.140).

\subsection{Statistical analysis}

Data were analyzed by IBMC SPSS $\odot$ Statistics version 21 (IBM $\odot$ Corp., Armonk, NY, USA) using descriptive statistics Chi-square, Fisher's exact test, independent-samples t-test, and paired-samples t-test. P-value less than 0.05 was considered to be significant.

\section{Results}

\subsection{Demographics}

Among 120 children included in this study, 61 (50.8\%) were male and 59 (49.2\%) were female. Among 78 patients in the ceftriaxone group, 37 were male and 41 were female. Also, among 42 patients in the ampicillin and cefotaxime group, 24 were male and 18 were female. Baseline characteristics of the patients in both groups are compared in Table 1. 


\subsection{Main results of hypotheses}

Mean $\mathrm{Ca} / \mathrm{Cr}$ ratio was $0.339 \pm 0.204$ in the ceftriaxone group and $0.236 \pm 0.159$ in the ampicillin and cefotaxime group. The difference was statistically significant $(\mathrm{p}=0.005)$. Table 2 compares the prevalence of normal and abnormal $\mathrm{Ca} / \mathrm{Cr}$ ratio in the two groups. There was no statistically significant difference between duration of hospitalization and $\mathrm{Ca} / \mathrm{Cr}$ ratio in the two groups. As shown in Table 3, there was no significant difference in $\mathrm{Ca} / \mathrm{Cr}$ ratio based on gender in the two groups ( $p>0.05$ ); also, there was no significant difference in $\mathrm{Ca} / \mathrm{Cr}$ ratio based on the age group ( $\mathrm{p}>0.05)$.

Table 1. Baseline characteristics of patients in both groups

\begin{tabular}{|l|l|l|l|}
\hline Variable & Classification & Ceftriaxone & Ampicillin and cefotaxime \\
\hline \multirow{3}{*}{ Gender (percentage) } & Male & $37(47.4 \%)$ & $24(57.1 \%)$ \\
\cline { 2 - 4 } & Female & $41(52.6 \%)$ & $18(42.9 \%)$ \\
\hline \multirow{2}{*}{ Age (years) } & $>1$ & $34(43.6 \%)$ & $15(35.7 \%)$ \\
\cline { 2 - 4 } & $<1$ & $44(56.4 \%)$ & $27(64.3 \%)$ \\
\hline Duration of hospitalization (days) & 2 & $24(30.8 \%)$ & $13(31 \%)$ \\
\cline { 2 - 4 } & 3 & $28(35.9 \%)$ & $17(40.5 \%)$ \\
\cline { 2 - 4 } & 4 & $26(33.3 \%)$ & $12(28.6 \%)$ \\
\hline $\mathrm{Ca} / \mathrm{Cr}$ ratio & $0.2 \pm 0.091$ & $0.195 \pm 0.092$ \\
\hline
\end{tabular}

Table 2. Comparison of the prevalence of normal and abnormal $\mathrm{Ca} / \mathrm{Cr}$ ratio in two groups

\begin{tabular}{|l|l|l|l|}
\hline \multirow{2}{*}{ Group } & \multicolumn{2}{|l|}{$\mathrm{Ca} / \mathrm{Cr}$ ratio } & p-value (Chi-square test) \\
\cline { 2 - 3 } & Normal & Abnormal & 0.03 \\
\hline Ceftriaxone & $63(80.8 \%)$ & $15(19.2 \%)$ & \\
\hline Ampicillin and cefotaxime & $40(95.2 \%)$ & $2(4.8 \%)$ & \\
\hline
\end{tabular}

Table 3. Comparison of duration of hospitalization, gender, and age group based on $\mathrm{Ca} / \mathrm{Cr}$ ratio

\begin{tabular}{|c|c|c|c|c|c|}
\hline \multirow[t]{2}{*}{ Variable } & \multirow[t]{2}{*}{ Group } & \multirow[t]{2}{*}{ Subgroups } & \multicolumn{2}{|l|}{$\mathrm{Ca} / \mathrm{Cr}$ ratio } & \multirow{2}{*}{$\begin{array}{l}\mathrm{p} \text {-value } \\
\text { (Chi-square) }\end{array}$} \\
\hline & & & Normal & Abnormal & \\
\hline \multirow{6}{*}{$\begin{array}{l}\text { Duration of } \\
\text { hospitalization }\end{array}$} & \multirow[t]{3}{*}{ Ceftriaxone (days) } & 2 & $20(31.7 \%)$ & $4(26.7 \%)$ & \multirow[t]{3}{*}{0.910} \\
\hline & & 3 & $22(34.9 \%)$ & $6(40 \%)$ & \\
\hline & & 4 & $21(33.3 \%)$ & $5(33.3 \%)$ & \\
\hline & \multirow{3}{*}{$\begin{array}{l}\text { Ampicillin and cefotaxime } \\
\text { (days) }\end{array}$} & 2 & $13(32.5 \%)$ & $0(0 \%)$ & \multirow[t]{3}{*}{0.596} \\
\hline & & 3 & $16(40 \%)$ & $1(50 \%)$ & \\
\hline & & 4 & $11(27.5 \%)$ & $1(50 \%)$ & \\
\hline \multirow[t]{4}{*}{ Gender } & \multirow[t]{2}{*}{ Ceftriaxone } & Male & $27(42.9 \%)$ & $37(47.4 \%)$ & \multirow[t]{2}{*}{0.097} \\
\hline & & Female & $36(57.1 \%)$ & $5(33.3 \%)$ & \\
\hline & \multirow[t]{2}{*}{ Ampicillin and cefotaxime } & Male & $22(55 \%)$ & $2(100 \%)$ & \multirow[t]{2}{*}{0.209} \\
\hline & & Female & $18(45 \%)$ & $0(0 \%)$ & \\
\hline \multirow[t]{4}{*}{ Age } & \multirow[t]{2}{*}{ Ceftriaxone (years) } & $>1$ & $24(38.1 \%)$ & $10(66.7 \%)$ & \multirow[t]{2}{*}{0.067} \\
\hline & & $<1$ & $39(61.9 \%)$ & $5(33.3 \%)$ & \\
\hline & \multirow{2}{*}{$\begin{array}{l}\text { Ampicillin and cefotaxime } \\
\text { (years) }\end{array}$} & $>1$ & $13(32.5 \%)$ & $2(100 \%)$ & \multirow{2}{*}{0.089} \\
\hline & & $<1$ & $27(67.5 \%)$ & $0(0 \%)$ & \\
\hline
\end{tabular}

\section{Discussion}

This study was done on 120 children with febrile infection who were admitted to Bandar Abbas pediatric hospital for comparison of hypercalciuria after intravenous injection of ceftriaxone or ampicillin and cefotaxime. We found that the $\mathrm{Ca} / \mathrm{Cr}$ ratio is significantly higher in the ceftriaxone group in comparison to the ampicillin and cefotaxime group.

\subsection{Comparison of study results with similar studies}

Takahisa Kimata et al. (8) have reported in their study in 2012 that urine $\mathrm{Ca} / \mathrm{Cr}$ ratio is significantly higher in patients using ceftriaxone in comparison to amoxicillin. The serum calcium level was similar in the two groups before and after the intervention. There was no significant relationship between gender or age and hypercalciuria in the two groups. Similar findings were reported in our study. In contrast to our findings, there was a significant 
relationship between duration of hospitalization and hypercalciuria in this study. The difference between the results of the two studies may be due to difference in sample size and race difference between the two groups. In contrast to our results Anoush Azarfar et al. found no significant difference in urine calcium to creatinine ratio in children receiving or not receiving ceftriaxone (9). The serum calcium level was not significantly different in the two groups before and after the study. This finding is similar to our findings. In this study, the researchers used placebo for the control group. We used ampicillin and cefotaxime in the control group. Both studies were carried out on Iranian children but the sample size was different in the two studies. Alper Otunctemur et al. have shown in their study that patients receiving ceftriaxone and cephalothin have higher levels of urine $\mathrm{Ca} / \mathrm{Cr}$ ratio regardless of having kidney stones or not. Our results confirm these findings. In this study, the urine calcium level was similar in all groups before intervention. After treatment, the urine calcium level increased in both patients with and without kidney stones. These findings are similar to the results of our study. Similar to our study, age and gender had no relationship with hypercalciuria in this study. Mohkam et al. have assessed the effect of ceftriaxone on incidence of kidney stones in children. In their research, 284 children were studied. The patients were under treatment with ceftriaxone for 9 to 10 days. All patients underwent ultrasonography on the first or second day of admission which was repeated at the end of the treatment. In complicated cases, the ultrasonography was repeated after 3 months. The baseline ultrasonography was similar in all patients. In the $2^{\text {nd }}$ ultrasonography, 4 out of 284 patients developed kidney stones. The patients who developed kidney stones in this study had similar $\mathrm{Ca} / \mathrm{Cr}$ ratio in comparison to other patients (10). Age and gender had no role in urine $\mathrm{Ca} / \mathrm{Cr}$ ratio. These findings were similar to our findings. Furthermore, Azita Fesharakinia et al. in 2013 studied 96 patients who were under treatment with ceftriaxone. In this study 6 patients developed kidney stones and 1 patient developed gallbladder stones. In this study, $\mathrm{Ca} / \mathrm{Cr}$ ratio was similar in these patients before and after study in both groups (11). Age and gender had no role in development of kidney stones as shown in our study. In this study, urine $\mathrm{Ca} / \mathrm{Cr}$ ratio was not measured.

\subsection{Study limitations}

Short duration of follow up in our patients limits the generalization of our findings. Ceftriaxone may have long-term complications in the urinary system which is not assessed in our study. Also, we have assessed only urine $\mathrm{Ca} / \mathrm{Cr}$ ratio. Using ceftriaxone or ampicillin and cefotaxime may have other complications which are not assessed in our study. We have only assessed urine $\mathrm{Ca} / \mathrm{Cr}$ ratio. It is not clear whether or not the increased levels of $\mathrm{Ca} / \mathrm{Cr}$ ratio increase the risk of kidney stones.

\section{Conclusions}

Based on the results of our study, ceftriaxone is associated with higher levels of $\mathrm{Ca} / \mathrm{Cr}$ ratio in comparison to ampicillin and cefotaxime in children with febrile bacterial infections. The results of similar studies are inconsistent and it's unclear whether or not the increased urine $\mathrm{Ca} / \mathrm{Cr}$ ratio increases the risk of kidney stones. Despite this we recommend using alternative regimens of antibiotics instead of ceftriaxone when it is possible.

\section{Acknowledgments:}

The paper was extracted from the results of a thesis by Dr. Nadia Parvar for fulfillment of specifications required for a specialty degree of pediatrics. The authors want to thank the Clinical Research Development Center of the Children Hospital, Hormozgan University of Medical Sciences, Bandar Abbas, Iran for their help and support.

\section{Conflict of Interest:}

There is no conflict of interest to be declared.

\section{Authors' contributions:}

All authors contributed to this project and article equally. All authors read and approved the final manuscript.

\section{References:}

1) Moreira Guimaraes Penido MG, de Sousa Tavares M, Campos Linhares M, Silva Barbosa AC, Cunha M. Longitudinal study of bone mineral density in children with idiopathic hypercalciuria. Pediatr Nephrol. 2012; 27(1): 123-30. doi: 10.1007/s00467-011-1952-4. PMID: 21779854.

2) Madani A, Kermani N, Ataei N, Esfahani ST, Hajizadeh N, Khazaeipour Z, et al. Urinary calcium and uric acid excretion in children with vesicoureteral reflux. Pediatr Nephrol. 2012; 27(1): 95-9. doi: 10.1007/s00467-011-1936-4. PMID: 21814729. 
3) Silverberg SJ, Lewiecki EM, Mosekilde L, Peacock M, Rubin MR. Presentation of asymptomatic primary hyperparathyroidism: proceedings of the third international workshop. J Clin Endocrinol Metab. 2009; 94(2): 351-65. doi: 10.1210/jc.2008-1760. PMID: 19193910, PMCID: PMC5393372.

4) Schwaderer AL, Srivastava T, Schueller L, Cronin R, Mahan JD, Hains D. Dietary modifications alone do not improve bone mineral density in children with idiopathic hypercalciuria. Clin Nephrol. 2011; 76(5): 341-7. doi: 10.5414/CN106943. PMID: 22000552.

5) Vezzoli G, Soldati L, Gambaro G. Update on primary hypercalciuria from a genetic perspective. J Urol. 2008; 179(5): 1676-82. doi: 10.1016/j.juro.2008.01.011. PMID: 18343451.

6) Curhan GC, Willett WC, Speizer FE, Stampfer MJ. Twenty-four-hour urine chemistries and the risk of kidney stones among women and men. Kidney Int. 2001; 59(6): 2290-8. doi: 10.1046/j.15231755.2001.00746.x. PMID: 11380833.

7) Zwart SR, Parsons H, Kimlin M, Innis SM, Locke JP, Smith SM. A 250 mug/week dose of vitamin D was as effective as a $50 \mathrm{mug} / \mathrm{d}$ dose in healthy adults, but a regimen of four weekly followed by monthly doses of 1250 mug raised the risk of hypercalciuria. $\mathrm{Br} \mathrm{J}$ Nutr. 2013; 110(10): 1866-72. doi: 10.1017/S000711451300113X. PMID: 23595003.

8) Kimata T, Kaneko K, Takahashi M, Hirabayashi M, Shimo T, Kino M. Increased urinary calcium excretion caused by ceftriaxone: possible association with urolithiasis. Pediatr Nephrol. 2012; 27(4): 605-9. doi: 10.1007/s00467-011-2038-z. PMID: 22038204.

9) Azarfar A, Esmaeeli M, Ravanshad Y, Bagheri S, Khodashenas E, Ghane-Sharbaf F, et al. Hypercalciuria following ceftriaxone a fact or myth. J Renal Inj Prev. 2015; 4(3): 101-3. doi: 10.12861/jrip.2015.20. PMID: 26468483, PMCID: PMC4594212.

10) Mohkam M, Karimi A, Gharib A, Daneshmand H, Khatami A, Ghojevand N, et al. Ceftriaxone associated nephrolithiasis: a prospective study in 284 children. Pediatr Nephrol. 2007; 22(5): 690-4. doi: 10.1007/s00467-006-0401-2. PMID: 17226043.

11) Fesharakinia A, Ehsanbakhsh AR, Ghorashadizadeh N. Ceftriaxone-associated nephrolithiasis in children. Iran J Pediatr. 2013; 23(6): 643-7. PMID: 24910741, PMCID: PMC4025120. 